Proceedings

\title{
Spatial-temporal analysis of urban eco-environmental quality of an urban area using geo-spatial techniques: The case of Dhaka megacity, Bangladesh
}

\author{
Muhammad Mainuddin Patwary ${ }^{1,2^{*}}$ \\ 1 Environment and Sustainability Research Initiative, Khulna 9208, Bangladesh; raju.es111012@gmail.com_ \\ (M.M.P.) \\ 2 Environmental Science Discipline, Life Science School, Khulna University, Khulna 9208, Bangladesh \\ * Correspondence: raju.es111012@gmail.com;
}

\begin{abstract}
This study determined the spatio-temporal changes of urban eco-environmental quality (UEEQ) of a rapidly growing megacity-Dhaka, Bangladesh, based on the Pressure-State-Response (PSR) framework. A comprehensive index with the combination of five vegetation indices and four urban indices that met the Pressure-State-Response (PSR) framework integrated through principal component analysis (PCA) was developed to assess urban eco-environmental quality index (UEQI) in 2000 and 2020. The results found that the high proportion of UEQI in the study area was very poor to poor and clustered in the city center and western periphery. Moran's I and LISA confirmed the non-randomness pattern of UEQ in the city. The findings could provide a quantitative foundation for decision makers to balance eco-environmental quality and urbanization.
\end{abstract}

Keywords: Urban eco-environmental quality index (UEQI); Sustainable development goal; Dhaka City; Global South

Citation: Patwary, M.M.; 2022, Spatial-temporal analysis of urban ecoenvironmental quality of an urban area using geo-spatial techniques: The case of Dhaka megacity, Bangladesh. SUPTM 2022 conference proceedings sciforum-054574.

https://doi.org/10.31428/10317/10499

Publisher's Note: UPCT and Sciforum stays neutral with regard to jurisdictional claims in published maps and institutional affiliations.

Copyright: (C) 2022 by the authors. Submitted for possible open access publication under the terms and conditions of the Creative Commons Attribution (CC BY) license (https://creativecommons.org/license s/by/4.0/).

\section{Introduction}

According to the United Nations (UN), the world is home to a 4.2 billion urban population (United Nations, 2018). Despite the lower growth of urbanization, Asian cities belong to about $54 \%$ of the world's urban population and are estimated to host $66.2 \%$ of the urban population by 2050 (United Nations, 2018). Bangladesh, in particular, has been experienced an increasing trend of urbanization and the country's urban population has reached 59 million $(41.39 \%$ ) and is expected to reach $70 \%$ of urban population by 2060 (Patwary et al., 2020). Rapid urbanization exerted pressure on the urban environment resulting in a degradation of environmental quality and urban quality of life (Musse et al., 2018). Hence, there is a global concern to assess the urban environmental quality for achieving urban sustainable development.

Urban Eco-environmental Quality (UEQ) measures the environmental capacity of an urban area at a pace with human needs. Several previous studies have measured the UEQ that focused on a single aspect of the eco-environment such as the normalized difference vegetation index (NDVI), land surface temperature (LST), and land use land cover (LULC) (Zhang et al., 2021). However, a single indicator-based assessment cannot characterize the complexity of UEQ and overlooks many other eco-environmental components of the urban ecosystem (Zhang et al., 2021). In response to this issue, researchers
22 suggested incorporating multiple indicators to produce a comprehensive assessment of UEQ. Frameworks in previous studies were limited by considering the environment as static (Pramanik et al., 2021). To reduce this uncertainty, the present study focused on the pressure state response (PSR) framework to determine UEQ. Earlier studies have documented several environmental challenges in Dhaka City such as urban heat islands

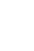

.
. 8

(

(
(1) .

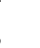
(4) 5 19 0 
(Dewan et al., 2021), air pollution, and environmental exposure-related health burdens (Siddiqui et al., 2020). However, we are unaware of studies that determine the urban ecoenvironmental quality of Dhaka City, Bangladesh. Therefore, this study is unique in the following ways: (1) the first to determine the UEQ in Bangladesh, and (2) consideration of spatio-temporal changes in UEQ using geo-statistical techniques.

\section{Materials and methods}

\subsection{Study area}

The study was conducted in Dhaka City, Bangladesh which is one of the fastestgrowing megacities in the world with a 14.2 million populations and an area of 304.17 $\mathrm{km}^{2}$. The climate of the city is tropical monsoon (hot and humid weather with seasonal variation). Unplanned urbanization growth has caused significant changes in the environmental quality of Dhaka City during the last decades (Dewan et al., 2021).

\subsection{Methods}

\subsubsection{Conceptual framework}

This study constructed an Urban Eco-environmental Quality Index (UEQI) using the Pressure-State-Response (PSR) framework. Urbanization growth was presented as pressure, ecological conditions were considered as state, and climate change indicators such as land surface temperature and moisture change were represented as response ( $\mathrm{Hu} \& \mathrm{Xu}$, 2018). We used the bareness index (BI), normalized difference built-up index (NDBI), urbanness index (UI) as pressure indicators; normalized difference vegetation index (NDVI), soil adjusted vegetation index (SAVI), and green vegetation index (GVI) as state indicators; and normalized difference moisture index (NDMI), tasselled cap transformation wetness index (TcWI) and land surface temperature (LST) as response indicators (Figure 1) following past research (Pramanik et al., 2021).

\subsubsection{Data}

Multi-temporal Landsat satellite images were used to develop different bio-physical indices and a composite index of UEQ. Landsat 5 (TM) and Landsat 8 (OLI-TIRS) imagery was collected between 2000 and 2020 to estimate indices. MODIS imagery were used to estimate LST. It was difficult to find cloud-free and well-matched satellite data during monsoon seasons. Accordingly, images that fell between December and January were collected for analysis. All data were collected and analyzed in Google Earth Engine (GEE).

\subsubsection{Construction of UEQ index}

The construction of the UEQ index consisted of a stepwise approach. First, water masking was performed with a modified normalized difference water index (MNDWI). Second, all variables were normalized to $0-1$ scale to reduce the data dimensionality. Third, the spatial principal component analysis (SPCA) was conducted with all normalized variables to produce weights for the combined indicators (Pramanik et al., 2021). Finally, a composite index was generated using the following equation:

$$
\mathrm{UEQI}=r_{1} \mathrm{PC}_{1}+r_{2} \mathrm{PC}_{2}+r_{3} \mathrm{PC}_{3}+\ldots \ldots \ldots \ldots+r_{n} \mathrm{PCn}
$$

where $r_{n}$ represents the contribution ratio of PC and $n$ is the number of PC The $r_{n}$ value was estimated using following equation:

$$
r_{n}=\frac{P_{i}}{\sum_{i=1}^{n} P_{i}}
$$

where $P_{i}$ are the eigenvalues of PCn 


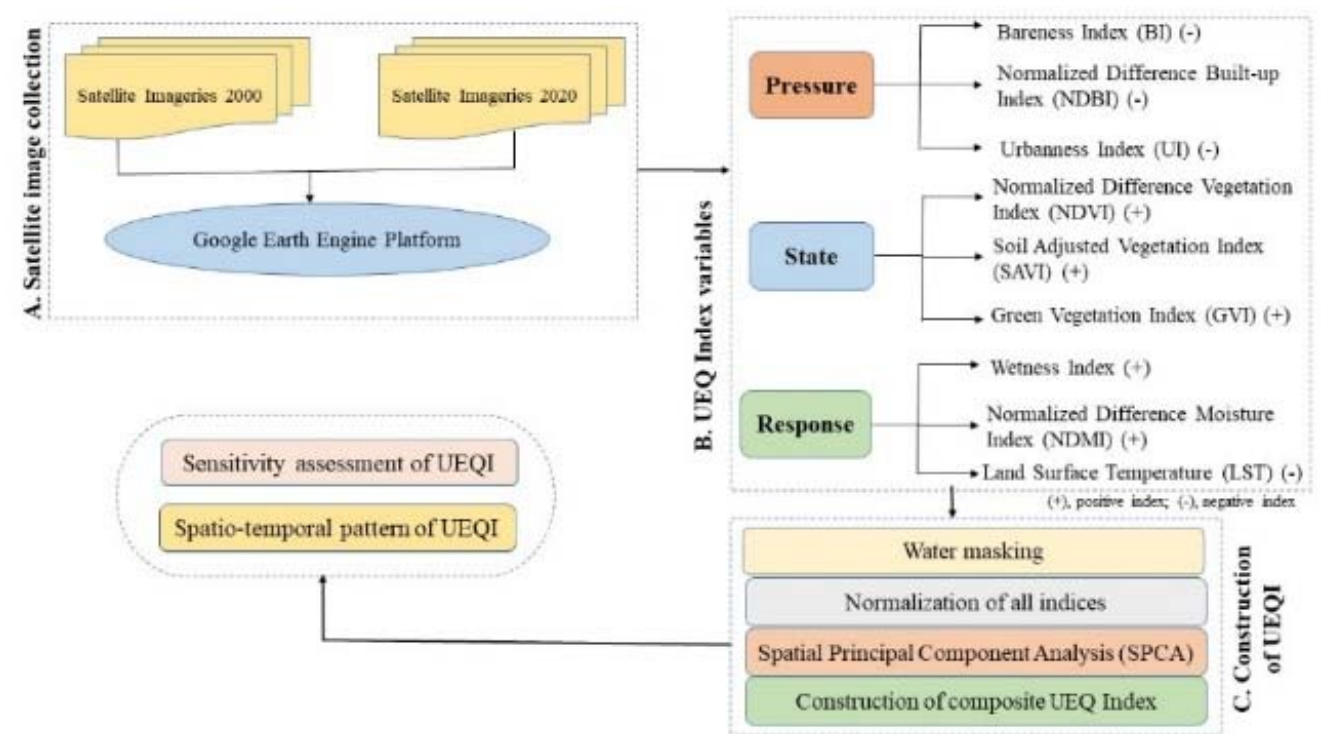

Figure 1. Analytical framework of the study.

The index was calculated, again rescaled to $0-1$, and categorized into five classes to determine eco-environmental quality levels of excellent (0.80-1.00), good (0.60-0.80), normal (0.40-0.60), poor (0.20-0.40), and very poor (0.00-0.20). Moran's I and local indicator of spatial autocorrelation (LISA) determined the spatial heterogeneity of urban eco-environmental quality.

\section{Results}

UEQI status was poor during the study period in Dhaka City. In 2000, only $30.12 \%$ of the area $\left(92.45 \mathrm{~km}^{2}\right)$ showed good to excellent UEQI, with this amount decreasing over time to only $23.86 \%$ in 2020 . In contrast, $36.08 \%$ of the area $\left(110 \mathrm{~km}^{2}\right)$ showed very poor UEQI during 2000. In 2020, the very poor status of UEQI of the study area increased to $47.38 \%\left(144.45 \mathrm{~km}^{2}\right)$. The amount of land with fair UEQI was $23.27 \%\left(70.94 \mathrm{~km}^{2}\right)$ in 2000 and $22.02 \%\left(671.2 \mathrm{~km}^{2}\right)$ in 2020 .
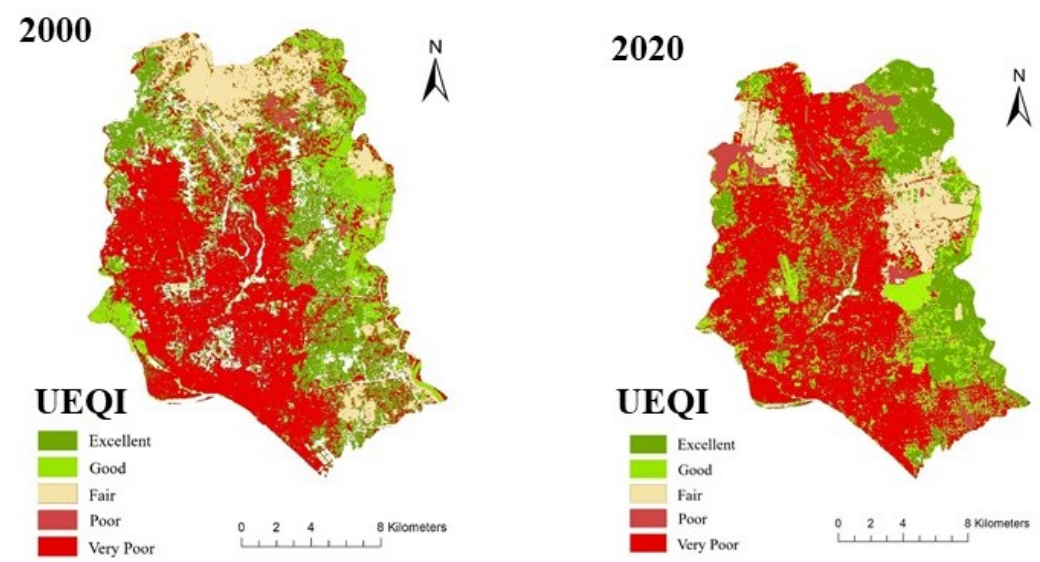

Figure 2. Spatial and temporal pattern of UEQI in Dhaka City in 2000 and 2020.

Figure 2 shows the spatial distribution of five UEQI classes in Dhaka City during 2000 and 2020. Poor and very poor statuses were observed in the city center and along the western periphery in 2000. A similar pattern was observed in 2020 along with an extension towards the northern part of the city. In contrast, good status of UEQI was concentrated at the eastern side from the city center.

Figure 3 shows the spatial auto-correlational analysis of Dhaka City in 2000 and 2020. The map represents statistically significant clusters and outliers of UEQI. A high UEQI 
value ('HH' cluster) indicates good and excellent quality UEQI and the 'LL' cluster represents the opposite. The ' $\mathrm{HH}^{\prime}$ cluster was concentrated in the outskirt of the city boundaries during both years whereas the 'LL' cluster was mostly found in the city center.
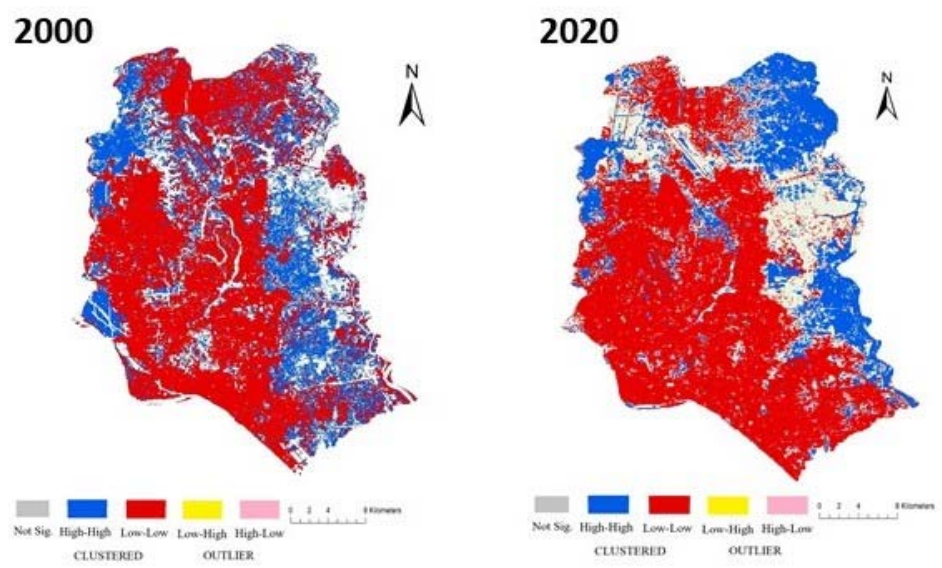

Figure 3. Multi-temporal cluster and outlier of UEQI in Dhaka City in 2000 and 2020.

\section{Conclusion}

The results found that the high proportion of UEQI in the study area was very poor to poor and clustered in the city center and western periphery. The findings and observation of this study could help policymakers to balance the ecological condition of the area in response to urbanization, which in the long run, might help with building climate-resilient smart cities.

Funding: This research received no external funding.

Conflicts of Interest: The authors declare no conflict of interest.

\section{References}

Dewan, A., Kiselev, G., \& Botje, D. (2021). Diurnal and seasonal trends and associated determinants of surface urban heat islands in large Bangladesh cities. Applied Geography, 135. https://doi.org/10.1016/j.apgeog.2021.102533

$\mathrm{Hu}, \mathrm{X} ., \& \mathrm{Xu}, \mathrm{H}$. (2018). A new remote sensing index for assessing the spatial heterogeneity in urban ecological quality: A case from Fuzhou City, China. Ecological Indicators, 89, 11-21. https://doi.org/10.1016/j.ecolind.2018.02.006

Musse, M. A., Barona, D. A., \& Santana Rodriguez, L. M. (2018). Urban environmental quality assessment using remote sensing and census data. International Journal of Applied Earth Observation and Geoinformation, 71, 95-108. https://doi.org/10.1016/j.jag.2018.05.010

Patwary, M. M., Ashraf, S., \& Shuvo, F. K. (2020). Land use changes and their effects on urban ecosystem services value: A study of khulna city, bangladesh. 2020 IEEE India Geoscience and Remote Sensing Symposium, InGARSS 2020 - Proceedings, 62-65. https://doi.org/10.1109/InGARSS48198.2020.9358927

Pramanik, S., Areendran, G., Punia, M., \& Sahoo, S. (2021). Spatio-temporal pattern of urban eco-environmental quality of Indian megacities using geo-spatial techniques. https://doi.org/10.1080/10106049.2021.1903578. https://doi.org/10.1080/10106049.2021.1903578

Siddiqui, S. A., Jakaria, M., Amin, M. N., Al Mahmud, A., \& Gozal, D. (2020). Chronic air pollution and health burden in Dhaka city. In European Respiratory Journal (Vol. 56, Issue 2). https://doi.org/10.1183/13993003.00689-2020

United Nations. (2018). 2018 Revision of World Urbanization Prospects I Multimedia Library - United Nations Department of Economic and Social Affairs. https://www.un.org/development/desa/publications/2018-revision-of-world-urbanization-prospects.html

Zhang, T., Yang, R., Yang, Y., Li, L., \& Chen, L. (2021). Assessing the urban eco-environmental quality by the remote-sensing ecological index: Application to Tianjin, North China. ISPRS International Journal of Geo-Information, 10(7). https://doi.org/10.3390/ijgi10070475 